\title{
Understanding climatic controls on sea-ice transport pathways in the Arctic Ocean
}

\author{
Andrey Proshutinsky, Mark Johnson, Tatiana Proshutinsky \\ Institute of Marine Science, University of Alaska Fairbanks, P.O. Box 757220, Fairbanks, AK 99775-7220, U.S.A.
}

\begin{abstract}
The primary goal of this paper is to demonstrate the dependence of Arctic Ocean sea-ice transport pathways on climate variations. We build our analysis on the results of Proshutinsky and Johnson (1997), Johnson and others (1999), Polyakov and others (1999) and Proshutinsky and others (1999), where we have shown that wind-driven ice motion and upper ocean circulation alternate between anticyclonic and cyclonic states. Shifts between regimes occur at 5-7 year intervals, resulting in a $10-15$ year period. The anticyclonic circulation regime has been observed in our model results for 1946-52, 1958-62, 1972-79, 1984-88 and 1998-present. The cyclonic circulation regime prevailed during 1953-57, 1963-71, 1980-83 and 1989-97. The regime shifts are fundamentally important to understanding the Arctic's general circulation and particularly useful for estimating pollution transport by sea ice and surface waters. It is important to pollution studies to understand which circulation regime prevails. Initially, we simulate trajectories of a non-reactive, conservative soluble tracer. Results from this research demonstrate realistic potential flow pathlines and we describe how those pathlines change in response to climate forcing. These results can be used to aid current and future scenario risk assessments and may provide management agencies with the tools to determine where risks from contaminants might exist.
\end{abstract}

\section{INTRODUCTION}

In this paper we focus on variations in sea-ice trajectories due to climate forcing. We do not discuss in detail major aspects and problems related to true contaminant transport with sea ice and water in the Arctic Ocean because this information is well presented in the publications and workshop proceedings of the International Arctic Seas Assessment Project (IASAP), the Office of Naval Research's Arctic Nuclear Waste Assessment Program (ANWAP) and the Arctic Monitoring and Assessment Program (AMAP). For a review of the status of ocean and ice contaminant transport modeling in the Arctic, see Preller (1999) and Preller and Cheng (1999). Results of analyses of contaminant transport based on calculations of backward and forward trajectories from observed contaminated sea ice using Arctic drifting-buoy data were presented by Pfirman and others (1997). In the more recent works, S. Pfirman (personal communication 2000) showed that between 1979 and 1992 there are significant variations in the fate of contaminants entrained in sea ice formed on various Siberian seas. Zhang and others (1999) and Maslowski and others (2000) have shown the same results using their highresolution coupled ice- ${ }^{-}$ocean model forced by atmospheric fields for 1979-93. Here we demonstrate that climate shifts have occurred at least five times in the past 50 years, and speculate that signatures of these regimes can probably be found in the records of sedimentation, rates of coastal

\footnotetext{
* Present address: Physical Oceanography Department, Woods Hole Oceanographic Institution, MS \#29, 360 Woods Hole Road, Woods Hole, MA 02543, U.S.A.
}

erosion, and spatial and temporal variability of the other environmental parameters characterizing the behavior of the Arctic system.

\section{TWO GIRGULATION REGIMES}

We identify two regimes of the Arctic-system decadal variability which correspond to the anticyclonic and cyclonic circulation of the Arctic atmosphere and polar ocean with "cold and dry" and "warm and wet" atmospheres, and "cold and salty" and "warm and fresh" ocean water, respectively. Shifts from one regime to another are forced by changes in location and intensity of the Icelandic Low and the Siberian High. The theory of two regimes, definitions and models used for analyses are presented in Proshutinsky and Johnson (1997), Johnson and others (1999) and Proshutinsky and others (1999). In Proshutinsky and Johnson (1997), a twodimensional, barotropic coupled ice-ocean model was forced by winds, river runoff and an imposed but realistic sea-level slope between the Pacific and the Atlantic Oceans. A time series of simulated sea-level gradients (Fig. 1, lower panel, yellow and red bars) was constructed according to the procedure described in Proshutinsky and Johnson (1997; see section 3.2, p. 12,505 and figs 8-10). Positive sea-level gradients (Fig. 1, yellow bars) mean that the sea level in the center of the Arctic basin is higher than along coastlines and that the circulation is anticyclonic (clockwise). Negative sealevel gradients (red bars) have a lowered central sea level and increased sea level along coastlines, and the circulation is cyclonic (counterclockwise).

Here we present new results of the circulation regime definition based on EOF analysis of the simulated seasurface height ( $\mathrm{SSH})$ time series. The expansion coefficients 
Seo level heights. First EOF mode, $43 \%$

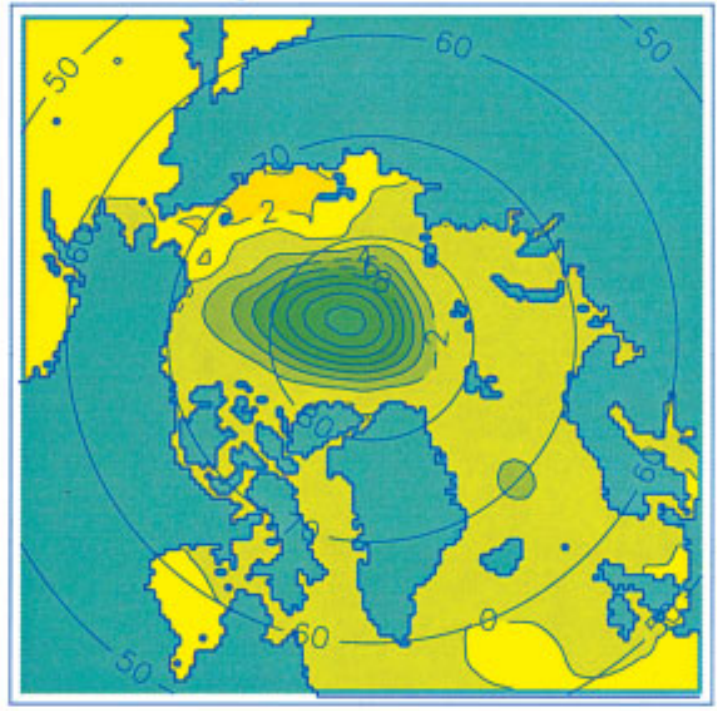

Seo level. The first EOF mode (43\%)

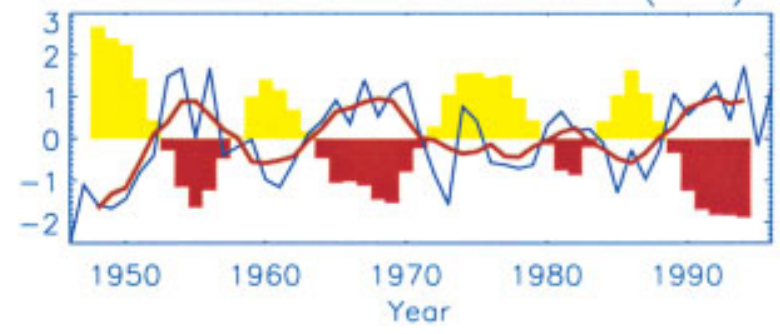

Fig. 1. Results of the EOF analysis of SSHs simulated for the period 1946-97. Upper panel shows the first mode pattern of the SSH anomaly (cm) and represents $43 \%$ of the anomaly variance. The lower panel shows SSH gradients (yellow and red bars) as defined by Proshutinsky and Fohnson (1997), and time series of the first EOF mode of SSH extension coefficient (blue and red lines). Blue line depicts annual mean value, and red lines shows 5 year running-mean data.

time series for the first empirical orthogonal function (EOF) mode is shown in Figure 1 (lower panel, blue and red lines). The first EOF pattern of the simulated annual mean $\mathrm{SSH}$ accounts for $43 \%$ of the SSH anomaly variance (Fig. 1, top panel). The second and third modes (not shown) represent $26 \%$ and $8 \%$ of the $\mathrm{SSH}$ anomaly variance, respectively, and are not discussed further.

The first EOF mode of SSH variability we call the Arctic Ocean Oscillation (AOO). This pattern is very similar to our figure 9 in Proshutinsky and Johnson (1997). SSH anomaly for the years with negative AOO index (Fig. 1, lower panel) corresponds to the anticyclonic circulation regime, and the $\mathrm{SSH}$ anomaly with the positive AOO index corresponds to the cyclonic circulation regime. The AOO correlates very well with the time series of sea-level gradients (bars in Fig. 1), which is consistent with our empirical definition of two circulation regimes based on sea-level gradients.

\section{SEA-ICE AND WATER-TRANSPORT PATHWAYS}

Understanding the two circulation regimes is useful for investigating the temporal and spatial variability of ice, water and pollutant transport in the Arctic Ocean. To investigate this variability we calculate ice and water trajectories based on hourly mean velocities from our two- dimensional
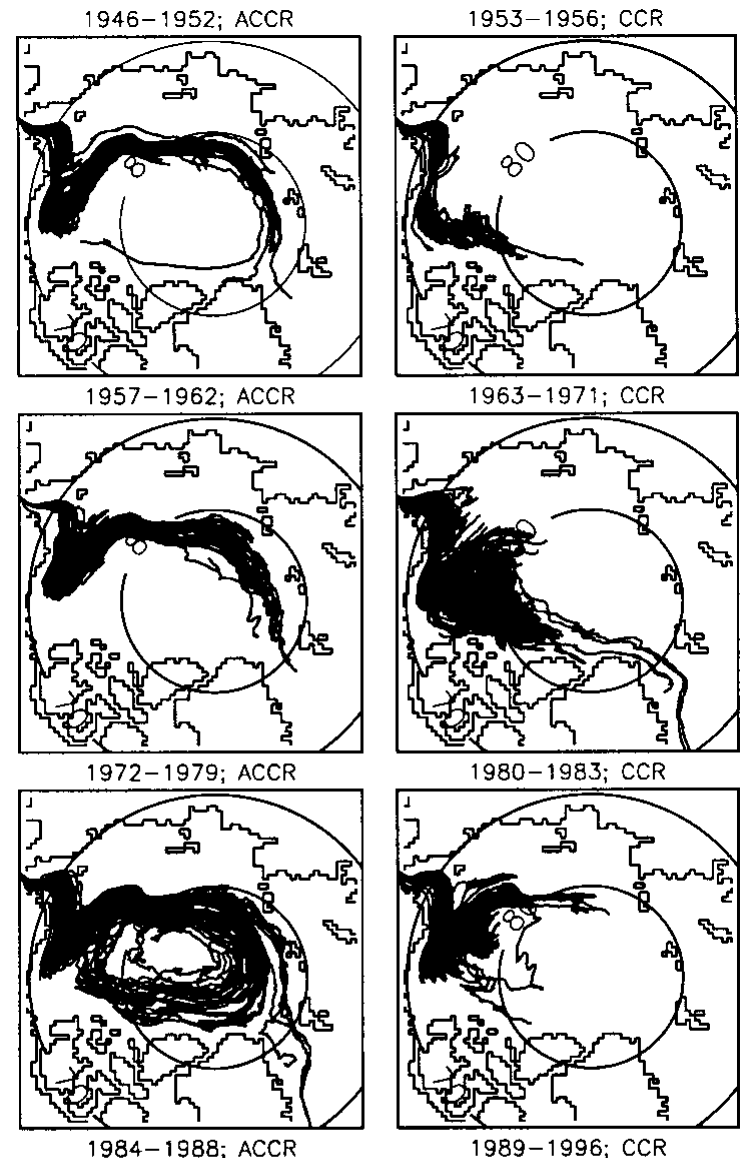

$1963-1971 ;$ CCR

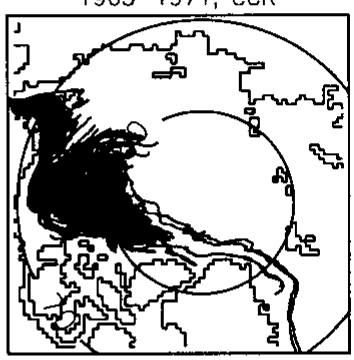

1980-1983; CCR

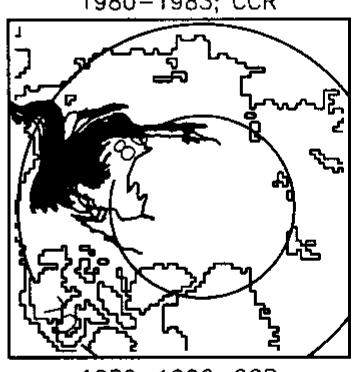

1989-1996; CCR
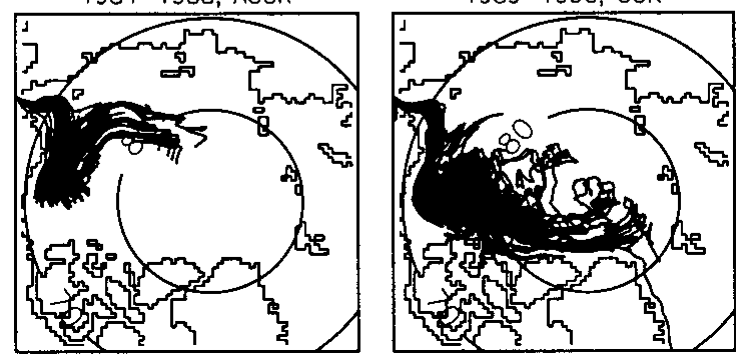

Fig. 2. Water-marker trajectories originating in Bering Strait for the periods of anticyclonic (left column) and cyclonic (right column) circulation regimes.

coupled ice-ocean model. Water parcels were released monthly in the mouths of major Arctic rivers (Mackenzie, Kolyma, Indigirka, Lena, Khatanga, Ob, Yenisei, Pechora) and in the Bering Strait for the period 1946-97. For example, in Figures 2-4 we present trajectories of water and ice markers released monthly originating in the Bering Strait and the Kara Sea (mouth of Ob River) for periods of anticyclonic and cyclonic regimes. Water markers moving with vertically averaged velocities in the upper $200 \mathrm{~m}$ layer have comparatively stable trajectories (Fig. 2) following bathymetric features and are consistent with the two circulation regimes. In the years of anticyclonic regimes (left column in Fig. 2), parcels released at Bering Strait have trajectories with anticyclonic rotation and follow the well known Trans-Arctic drift. In the years with the cyclonic regime (right column in Fig. 2), the pathways of water transport are shifted toward the Canadian Arctic and are cyclonic. In this case, water parcels or contaminants distributed in the upper ocean do not penetrate to the central Arctic.

Trajectories of ice markers originating in the Bering Strait (Fig. 3) are more variable because of the direct influence of wind. Ice pathways cross all regions in the Arctic basin, with 


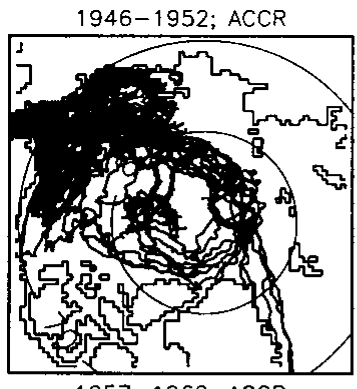

1957-1962; ACCR

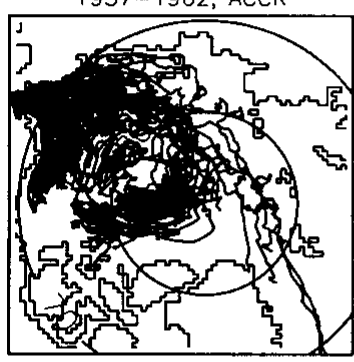

1972-1979; ACCR

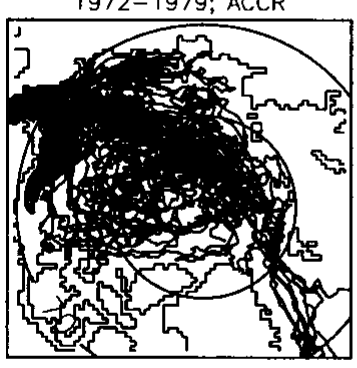

984-1988; ACCR
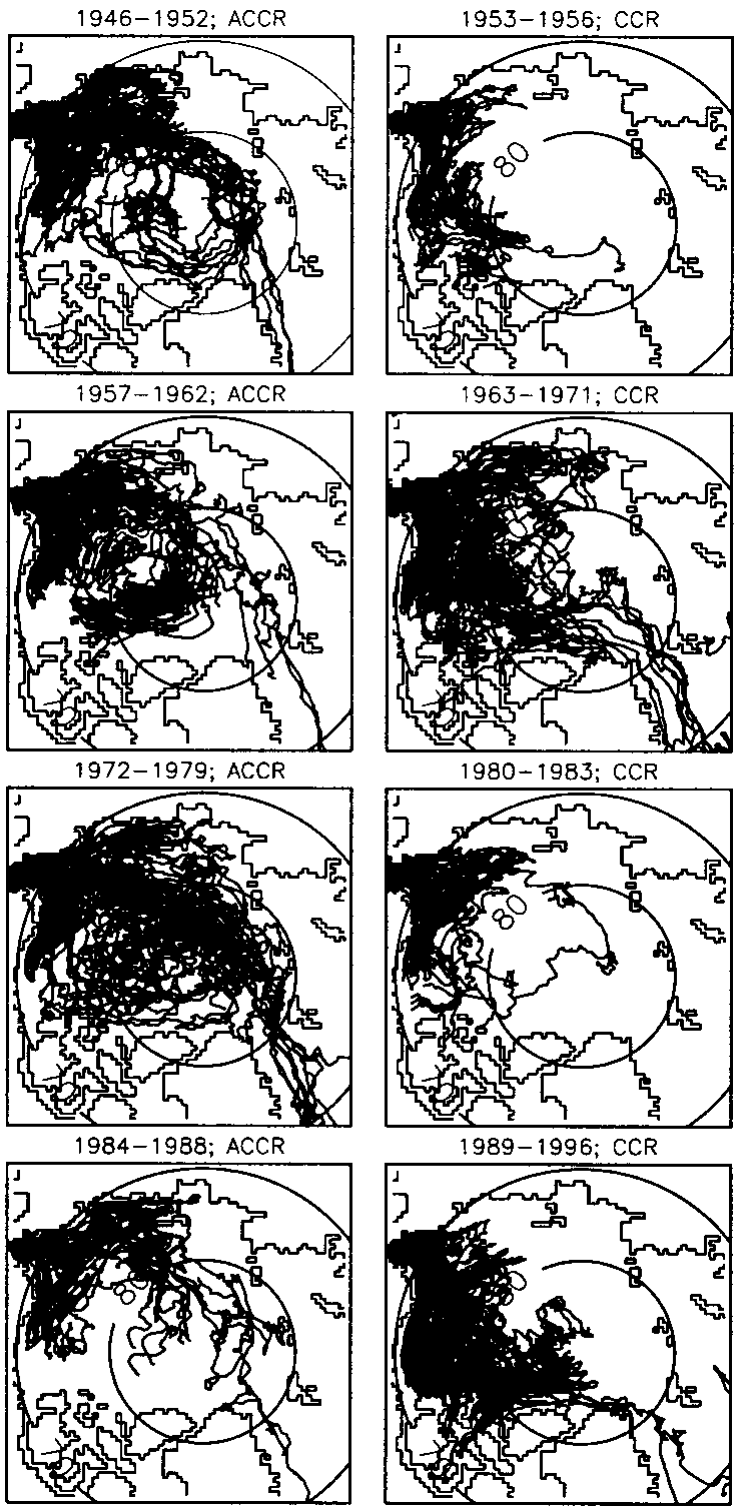

963-1971; CCR

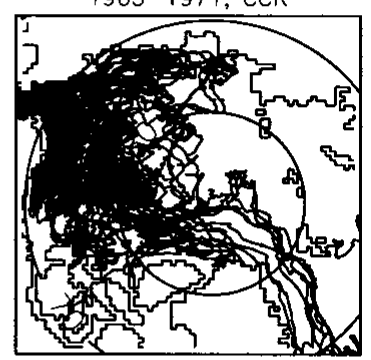

1980-1983; CCR

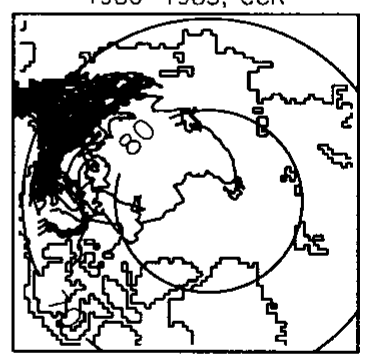

1989-1996; CCR

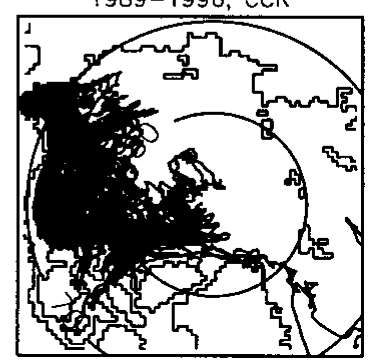

Fig. 3. Ice-marker trajectories originating in Bering Strait for the periods of anticyclonic (left column) and cyclonic (right column) circulation regimes.
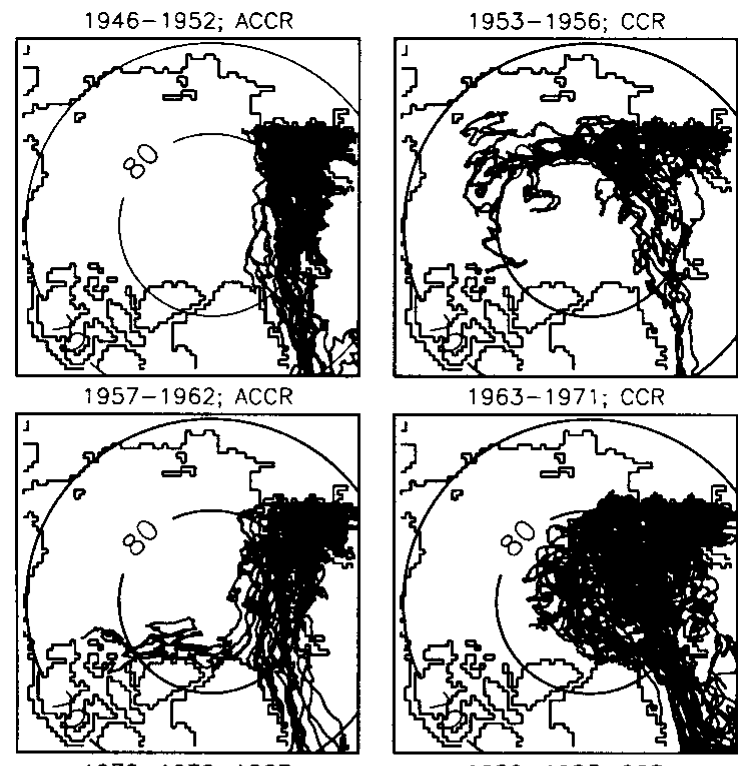

1963-1971; CCR
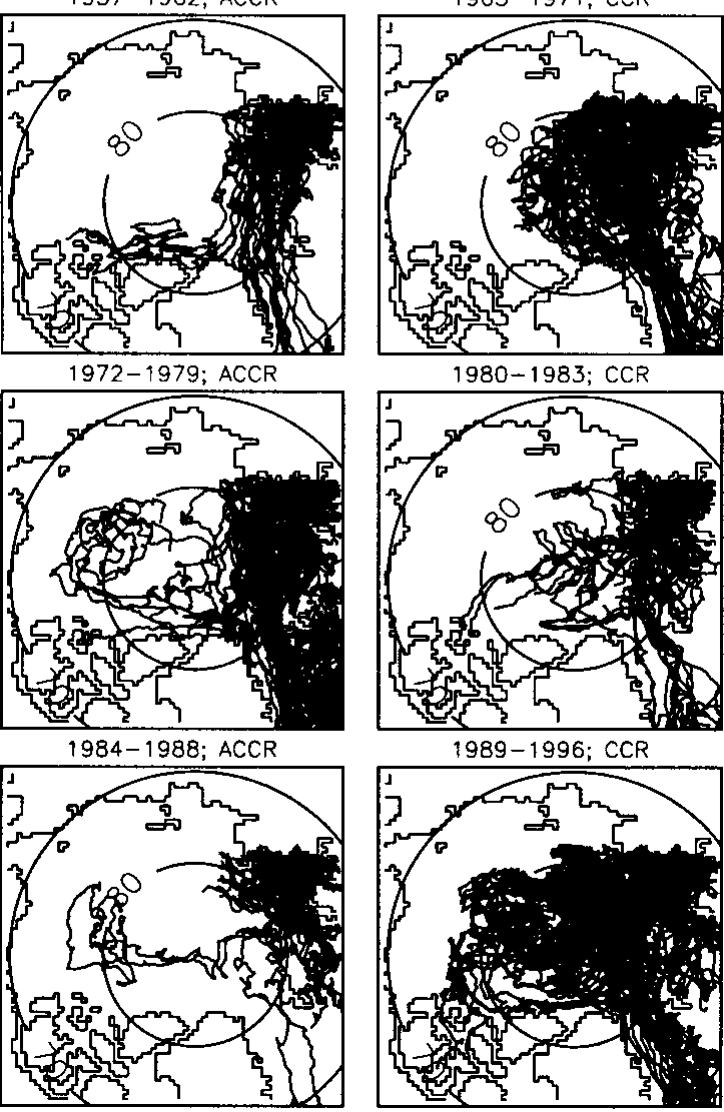

1989-1996; CCR

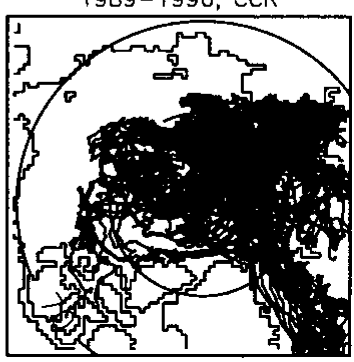

Fig. 4. Ice-marker trajectories originating in $\mathrm{Ob}$ river for the periods of anticyclonic (left column) and cyclonic (right column) circulation regimes. a maximum concentration in the Beaufort Sea and along the core of the Trans-Arctic drift during years with the anticyclonic regime. But in the years with the cyclonic regime, their paths are very similar to water parcels. They tend to be concentrated in the Chukchi and Beaufort Seas and move toward Fram Strait along the Canadian Archipelago, avoiding the central Arctic basin.

Ice parcels originating in the East Siberian and Laptev Seas (not shown) move to the east and west as a function of the regime type. Pollutants from the Kolyma river can reach the coastal waters off Alaska during the cyclonic circulation regime.

Trajectories of ice markers from the Kara Sea (Fig. 4) for the anticyclonic years are shifted toward the Barents Sea, and ice markers move directly to Fram Strait. If an anticyclonic regime lasts long enough, some ice markers can be involved in the central Arctic anticyclonic circulation. During years with the cyclonic circulation regime, the trajectories of ice markers originating in the Kara Sea are shifted toward the central Arctic, and their lifetime in the Arctic basin is much longer than during the anticyclonic regime.

Pollutant concentration was simulated using the above- discussed water and ice trajectories. We assumed that at every time-step each "pollutant particle" leaves an amount of its pollution. Summing this amount over time gives a "concentration". To have a high concentration of pollution in a region, either (1) many particles pass over the region, or (2) a particle remains in the region for an extended period. Analysis of this conditional concentration (not shown) shows that there are a few regions with high potential pollutant concentration: the continental slope of the Siberian seas, the core of Trans-Arctic current, regions with prevailing local cyclonic circulation and, of course, regions near a source of pollution. Analysis of these data allows us to speculate that hypothetical sediment cores must have a layered structure with contaminants from different sources. Thickness of the layers and their composition will depend on the duration of the circulation regime. Based on this approach, Bischof and Darby (1997) analyzed ice-rafted debris in four Arctic sediment cores and found evidence of regimes similar to our cyclonic and anticyclonic circulation regimes in the Arctic Ocean within the last 700000 years, although the duration of their regimes is much longer than the decadal scale discussed here. 


\section{GONCLUSIONS}

Understanding climatic controls on transport processes is useful for investigating the temporal and spatial variability of ice, water and pollutant distribution in the Arctic Ocean. The two-climate regime approach may help answer questions related to observed variability of Arctic environmental variables, including ice and water transport through different straits, sediment and pollutant transport, and reconcile the different conclusions among scientists who have analyzed hydrographic data, water circulation, ice drift, sediments and contaminants during different climate states.

These results are also important for the estimation of land--shelf and shelf-basin interactions. The following is a hypothesis for future research in this direction. We conclude that the two climate states, anticyclonic and cyclonic, dominate interannual variations in environmental parameters (AOO first mode describes $43 \%$ of sea-level height variance). Our results reveal significant differences among atmosphere, ice and ocean processes during the anticyclonic and cyclonic regimes in the Arctic Ocean and its marginal seas. Based on existing data, results of numerical experiments and our previous work (Proshutinsky and Johnson, 1997; Johnson and others, 1999; Polyakov and others, 1999; Proshutinsky and others, 1999), we conclude that during the anticyclonic circulation regime the prevailing processes lead to increases in atmospheric pressure in the Arctic, in ice concentration and ice thickness, river runoff and surface water salinity, as well as to decreases in air temperature, wind speed, number of storms, precipitation, permafrost temperatures, coastal sea level and surface water temperature. As a result of the dynamic-thermodynamic processes, we speculate that the rate of land-shelf and shelf-basin interactions (transport of ice, fresh water, sediments, pollutants) is lower than usual during the anticyclonic circulation regime.

During the cyclonic circulation regime, the prevailing processes lead to increased air and water temperatures, wind speed, number of storms, open-water period, and heights of wind waves, and to decreases in ice thickness and ice concentration, river runoff, atmospheric pressure and water salinity. These processes enhance the magnitude and rate of land-shelf and shelf-basin interactions. Cross-shelf transport of sediments and contaminants is enhanced, and sediments and contaminants are flushed out of the coastal regions and shelves. This hypothesis is not yet confirmed, and we suggest that a fruitful subject of future research would be the examination of sediment cores to look for these decadal patterns.

\section{ACKNOWLEDGEMENTS}

This research has been supported by the Wadati fund of the Geophysical Institute, University of Alaska Fairbanks, and by a grant from the U.S. National Science Foundation (OPP 9806926). We thank S. Pfirman, W. Meier, and M. VanWoert for their helpful review of the manuscript.

\section{REFERENGES}

Bischof, J. and D. A. Darby. 1997. Mid- to Late Pleistocene ice drift in the western Arctic Ocean: evidence for a different circulation in the past. Science, 277(5322), 74-78.

Johnson, M. A., A.Yu. Proshutinsky and I.V. Polyakov. 1999. Atmospheric patterns forcing two regimes of Arctic circulation: a return to anticyclonic conditions? Geophys. Res. Lett., 26(11), 1621-1624.

Maslowski, W., B. Newton, P. Schlosser, A. J. Semtner and D. G. Martinson. 2000. Modeling recent climate variability in the Arctic Ocean. Geophys. Res. Lett., $27(22), 3743-3746$.

Pfirman, S. L., R. Colony, D. Nürnberg, H. Eicken and I. Rigor. 1997. Reconstructing the origin and trajectory of drifting Arctic sea ice. $\mathcal{F}$. Geophys. Res., 102 (C6), 12,575-12,586.

Polyakov, I. V., A. Yu. Proshutinsky and M. A. Johnson. 1999. The seasonal cycles in two regimes of Arctic climate. f. Geophys. Res., 104(Cl1), 25,761-25,788.

Preller, R. H. 1999. A review of the status of ocean and ice contaminant transport modeling in the Arctic. In Modeling and Sources: a Workshop on Techniques and Associated Uncertainties in Quantifying the Origin and Long-range Transport of Contaminants to the Arctic. Report and Extended Abstracts of the Workshop, Bergen, 14-16 June 1999. Vol. Annex 6. Stromsveien, Norway, Arctic Monitoring and Assessment Program Secretariat, 1-4. (AMAP Report 99:4.)

Preller, R. H. and A. Cheng. 1999. Modeling the transport of radioactive contaminants in the Arctic. Mar. Pollution Bull., 38(2), 71-91.

Proshutinsky, A.Yu. and M. A. Johnson. 1997. Two circulation regimes of the wind-driven Arctic Ocean. F. Geophys. Res., 102(C6), 12,493-12,514.

Proshutinsky, A.Yu., I.V. Polyakov and M. A. Johnson. 1999. Climate states and variability of Arctic ice and water dynamics during 1946-1997. Polar Res., 18(2), 135-142.

Zhang, Y., W. Maslowski and A.J. Semtner. 1999. Impact of mesoscale ocean currents on sea ice in high resolution Arctic ice and ocean simulations. 7. Geophys. Res., 104(C8), 18,409-18,429. 